\title{
Dein Growth Hacking Readiness Score
}

Es ist geschafft! Du hast bis hierher durchgehalten und damit auf jeden Fall Deinen persönlichen „Brutal-Finisher-Instinkt“ bewiesen - ein Must-have für einen guten Growth Hacker.

\section{Aber wie geht es jetzt weiter?}

Aus mittlerweile unzähligen Workshops kenne ich die Frage: „Womit soll ich denn jetzt anfangen?“ Meine Antwort war bislang immer: „Man muss schauen, wo Du genau stehst. Wo drückt der Schuh am meisten?" Hört sich aufwendig an, oder?

Damit Du sofort starten kannst, die wirklich richtig krassen Growth Hacks umzusetzen, haben wir den Growth Hacking Readiness Score entwickelt. Dieser Quick-Check gibt Dir eine kurze und knackige Antwort darauf, was Du tun musst, um Dein Start-up oder Dein Unternehmen mit Growth Hacking erfolgreicher zu machen. Zahlreichen Marketern, Produkt Managern und Start-up-Gründern konnten wir damit schon helfen.

Also, checke Deinen Growth Readiness Score auf: http://growthhackingscore. com/

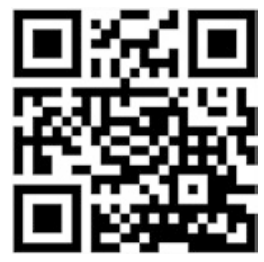

Hunderte Growth Hacks von den bekanntesten Growth Hackern weltweit wie Sean Ellis, Neil Pathel oder Gabriel Weinberg findest Du stets aktuell auf meiner Website http://www.growthhackingacademy.de. 